\title{
Tutorial on the fragmentation of the railway ballast particles and calibration methods in discrete element modelling
}

\author{
E. Juhász ${ }^{1}$, Sz. Fischer ${ }^{1, *}$ \\ ${ }^{1}$ Széchenyi István University, Department of Transport Infrastructure and \\ Water Resources Engineering \\ Egyetem tér 1, 9026 Győr, Hungary \\ *e-mail: fischersz@sze.hu
}

Submitted: 23/11/2020; Accepted: 01/02/2021; Published online: 05/02/2021

Abstract: This paper presents a short literature review related to the fragmentation of the railway crushed ballast particles. With the help of the processed articles with the main topic of discrete element modelling (DEM) we aim to provide some insight into the international achievements and forward progress of the subject. Rock materials as granular elements can be investigated from several perspectives. The elements can be examined in laboratory conditions purely from the quarry, or even by obtaining already fragmented particles from the real railway tracks. In addition, DEM models can be created by using computer software. This article tackles only a small segment of the literature. Though each DEM topic was unique, they all involved examination of degradation of particles in some way. This review focuses on model building, including particle construction and calibration. The selected publications do not cover the current state of the entire DEM research related to ballast degradation.

Keywords: ballast; degradation; DEM modelling

\section{Introduction}

Railroads ensure the biggest network for quick and secure, public and freight transportation on rails over the world [1]. 
Ballast bed is one of the most important railway track structural elements; it is composed of (mainly deep magmatic) rock particles built-in beneath the railway track, i.e. crossties (sleepers) and rails [2]. The aim of ballast is to ensure water drainage (dewatering) and structural support against loading due to railway vehicles, i.e. trains. Base rock type, rock quality, particle size distribution (i.e., gradation), as well as grain shape are the main characteristics of railway ballast materials that have to be considered during design process. Hard and strong ballast aggregates with preferable shape characteristics, i.e., angular 'stones', are high-priority for adequate strength and stability [3].

Railway ballast aggregates regularly consist of dolomite, rhyolite, andesite, gneiss, basalt, granite and also quartzite [4]; and they include medium to coarse gravel sized grains (i.e., 10-60 mm) with a lower quantity of pebble-sized grains [5, 6]. Good quality ballast material must contain angular grains, a high density, high shear strength, high persistence and hardness, high resistance against weathering, a rough surface, and a minimum of hairline cracks inside [7, 8]. The most important roles of ballast materials are to distribute and reduce forces affecting sleepers, provide horizontal resistance, and ensure quick dewatering. Ballast for high loads and stability must be angular, well graded, and dense (i.e., well compacted), but this structure hinders drainage [1].

The form of the particles keeps changing: the corners and edges brake from the particles and fine particles are modified, the result is a reduction of track quality (structural as well as geometrical). Finally, ballast screening and/or replacement will be required [9].

The railway track with all of its elements becomes continuously obsolete during usage. In addition to increasingly noticeable signs of slow failure on track elements, e.g., wear of rails, muddy area, etc. it is important to examine the causes of each problem and draw conclusions about the life expectancy associated with the causes and their prevention. Many authors around the world are concerned with the obsolescence of railway tracks, including degradation of ballast bed.

On a daily basis, more and more papers appear on the topic that help a lot in the research of the authors who concern similar research topic all over the world.

Articles on various topics mainly include the construction of new DEM models and the results of the running.

These will not be covered in these articles, because they have been presented in several of our previous publications, but the following factors also influence the ballast degradation:

- $\quad$ strength, hardness and durability of the grains, 
- density, and water absorption of the grains,

- the PSD (particle size distribution) of the particles,

- formal properties (which kind of particle form is dominant in the sets).

Naturally, a lot of other factors affect the lifetime of railway ballast beds, which are also at least as important as the DEM, but they cannot be completely modelled by using the DEM software.

The listed properties connect to the ballast grain form. Similar results can be achieved in literature published on granular materials, e.g., sand or concrete mixtures. Morphology as well as degradation are the most important factors to determine the deformation of railway ballast beds. However, these two factors can (and should) be examined in a number of ways, for which computer software is not necessarily the most ideal.

\section{Discrete Element Modelling (DEM)}

The DEM method is applied to model granular materials. This kind of computerbased simulation allows to virtually track the behaviour of the particles in the aggregate. Behaviour of the aggregate as a whole set is greatly influenced by the behaviour of the individual particles. With the help of this method, it is possible to take into account the element shape, which could be also one the most important physical parameters of the aggregate, and to determine the physical parameters of the model. When judging behaviour, it is necessary to simulate the element shape [10-16].

\subsection{Review of calibration approaches}

For model, exact prognoses can only be obtained if the values of the input parameters are precisely calibrated. All authors publishing on the topic apply various ways and methods to calibrate or determine the values of the parameters, however, relatively few authors have focused on improving and validating them [10].

There are two approaches in the literature for calibrating the input DEM parameters. The first way is to apply a method in which field tests or lab tests are executed to determine the main properties of a given substance. The test is then repeated numerically, with the parameters and results of lab and in situ test settings and procedures with the most accurate way [10].

The values of the DEM parameter are later iteratively modified until the expected mass 'reaction' is equal to the previously recorded one(s). A probable issue with this method is the mass 'reaction' of a numerical test may be affected by more than one parameter. This means: no individual solution is available because more than one 
combo of parameter values will occur in the same macro-mechanical behaviour. In this case, there is no guarantee that if the material is calibrated for one purpose, it will be exact and precise for the other one [10].

DEM models have been improved by presenting physical explanation to the parameters, but if this method is applied, the physical content of the parameters may be lost to some range [10].

\subsection{Modelling of element shape and size}

The particle size and shape distribution needs to be also taken into account as input parameters. Particle shape is one of the most relevant parameters to consider in DEM and must be precisely recorded if DEM is to be applied as a prognostic 'device'.

In nearly all DEM software, sphere-shaped (circles in 2D) elements are promoted because the contact is perceptible with efficiency and there is no need to determine the orientation of the particles. However, when spherical particles are used, the mass (inner) frictional or shear strength of the assembly is regularly set too low against the true particulate material [11]. The shear strength can be developed in several ways: using non-spherical particles, and/or by applying contact rolling friction [11, 12,13]. Among many other constitutive laws, for example rolling friction straightly limits the rotation of the elements by using a moment that resists rotation [11].

By increasing the particles' interlocking effect, non-spherical particles achieve this indirectly [14]. Particle rotation influences not only shear strength but also the expansion and localization of shear belts, so this parameter is not negligible [15].

Zhou et al. [15] compared 2D circular particles (disks) in detail against friction (i.e., rolling one) with non-spherical particles (nodules) without friction and stated that these two anti-rotation workings affected the macroscopic and microscopic action of particles [10].

\subsubsection{Shape of the particles}

Several parameters are important during the designing of the model, such as the shape modelling method, the usage, and the modelled particles. Nevertheless, it should be noted that the emphasis is on modelling the shape of the particles, combined with calibration steps, validating, and sensitivity phases, and not on the computative equations or formulas of various shape simulation methodologies [16].

Shapes experienced during the classification of the particles in ballast sets like flaky, rod-like and compact are also important types. To define the forms (morphology) several parameters need to be taken into consideration as follows: axis lengths, perimeter, volume, surface, etc. Furthermore, when the particles are 
designed roundness also matters. The surface of each particle can also be made up of polygons in DEM software in which a generalized version of the so-called areaweighted fabric tensor has been applied to a smooth surface. The tensor has several advantages over bounding box methods and based on the three eigenvalues of the tensor, the characteristics were proposed to serve classification. $[17,18]$

Angularity of particles is a main shape parameter that influences the mechanical characteristics (micro as well as macro ones) of particulate materials. Nearly all the actual particle angularity methodologies are founded on two-dimensional methods using grain predictions [16].

When analysing the particle shape, parameters are categorised into 3 groups: form, roundness and roughness. These are shown in Fig. 1.

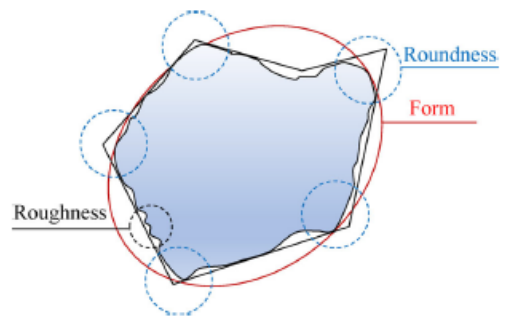

Figure 1. Presentation of the difference parameters [16]

According to some authors, the key to angularity is to identify the corner. The angle is defined by examination in contrast to the curvature of the grain face with the maximum inscribed circle (in three-dimensional cases: the maximum inscribed sphere, ball). The curvature of the grain face becomes one of the most relevant necessity for both edge/corner identification and angularity assessment [16].

Edge/corner identification process created on the scheduled interpretation (threedimensional mode of Wadell's definition):

- reconstructs the surface of the particle using a triangular mesh,

- calculates the local curvature of all vertices on the reconstructed surface,

- check that the vertex meets both the curvature and the associated relative conditions

- the vertex is considered to be a vertex,

- the corner vertices and the vertices within the single ring are defined as corner portions [16]. 
A new 3D particle angularity estimation method is proposed for triangle mesh three-dimensional particle models. First, the edges (corners) of the particle are referred by admitting the concepts of surface curvature and relative related area. The sphere is then evaluated with a ball filling approach. With respect to edge/corner identification, the concept of RSt (Ci) relative related area has been shown to adequately differentiate between angularity and confined features, allowing the expected methodology to reject confined high curvature features and thereby necessarily improve its certainty. To test the dependability of the proposed method, three-dimensional elements were generated from the 2-contour by application of an amorphological preservation principle [16].

There are plenty of methods to describing particles, only one source document contains 42 different quantities and their interpretation, usability, and practical application which are adaptable to research. These descriptions could be categorized qualitative or quantitative. [17]

\subsection{Comparison of $2 \mathrm{D}$ and $3 \mathrm{D}$ angularity}

The outcomes of the expected methodology are consistent with the outcomes of the corresponding 2D contour. In addition, the proposed method is examined in contrast with other three-dimensional angularity estimation methodologies, and the outcome looks promising. The advantage of the expected methodology is that its computation is not affected by subjective factors such as projective direction, optic contrasting, or non-objectively collected corner sections.

In addition, the expected methodology can be used to various particle models. The main goal of the expected methodology is to help engineers and scientists investigate the relationships between particle angularity and the mechanic behaviour of granular materials.

Two disadvantages need to be optimized in this regard:

a) accuracy of the assessment is affected by the curvature assessment algorithm performed. To be able to lower this effect, a high density triagonal mesh has to be used, that will increase the time-consumption of the calculation.

b) when applying the ball filling methodology, a high density ball assembly is needed to derive adequate corner spheres for accurate angularity estimation and thus increase the calculation effort.

The expected methodology is going to be farther optimized in the future. Future investigation will focus on combining this methodology with other DEM programs, 
such as the Particle Flow Code (PFC), to study whether the characteristics of particulate matter are affected by particle morphology [19].

\subsection{Particle generation with clumping}

There are several available programs, e.g. PFC [20], EDEM Simulation [21], Yade-DEM [22], etc., which have already been presented by the authors in their previous publications [10]. Some of these software are very costly, the others can be regulated by very complicated form. The authors applied $\mathrm{PFC}^{3 \mathrm{D}}$ software to build and run their model. The test bases are quite analogous, in this way in the first step the authors found PFC ${ }^{3 \mathrm{D}} 4.0$ adequate for "testing" DEM and are familiar with this methodology. As the modelling of granular materials (i.e., railway ballast) as balls showed non-correct behaviour (singularities in the computations), the application of clusters was necessary in order to achieve more realistic outcome. [23].

The model was approximated based on an existing laboratory examination, which are shown in Fig. 2 and Fig. 3.

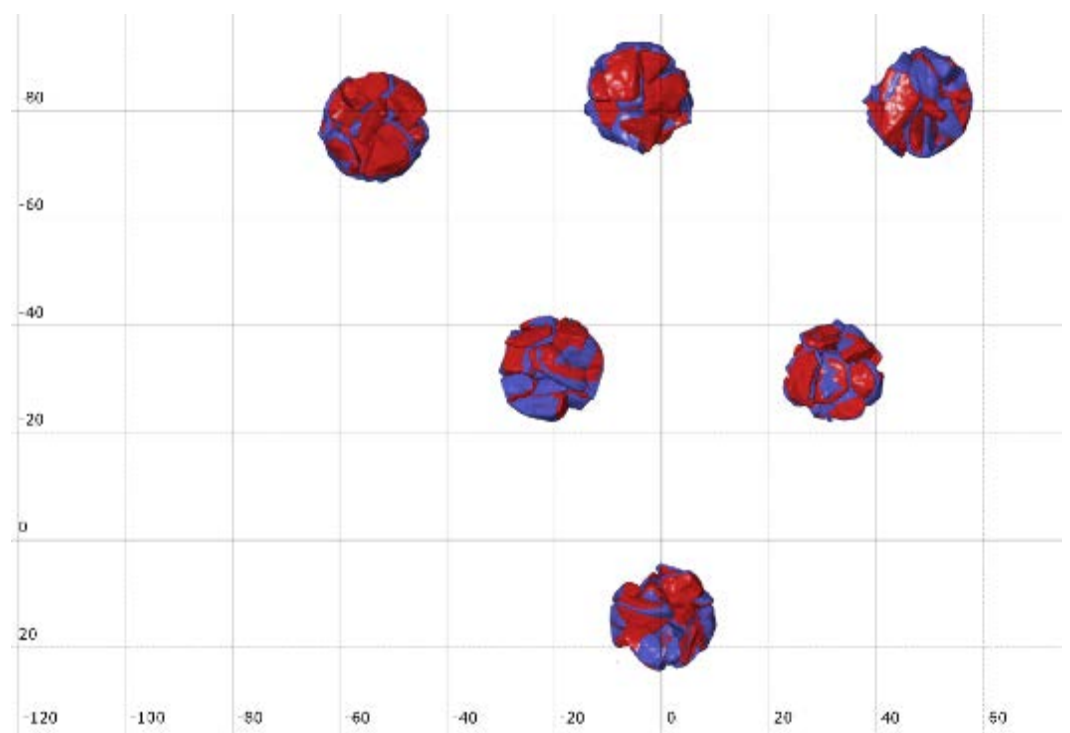

Figure 2. CT scans from the uniaxial compression tests with granules $4 / 8 \mathrm{~mm}$ material (top view) - red colour for before load and blue colour for after load [23] 


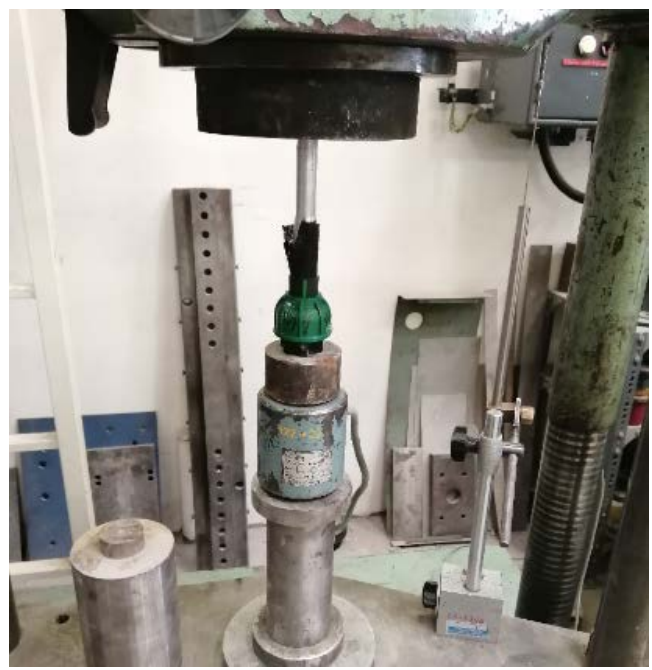

Figure 3. The laboratory test assembly [23]

The images after the model and the load steps are shown below on Fig. 4.

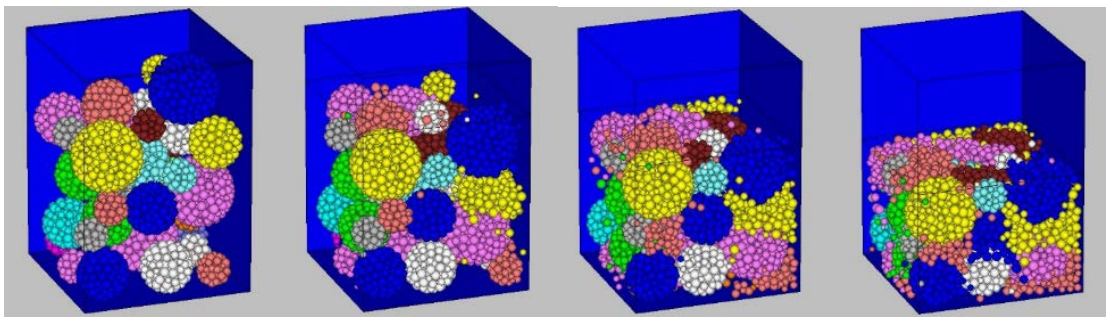

Figure 4. The gradual compression, in which the macroparticles are reduced to microparticles [23]

Scientists can model grains more realistically by creating polyhedral shaped elements. They can be created manually or randomly (e.g., with 3D scanner, shown in Fig. 5.), estimating the geometry of rocks. An entire set of individual elements can be assembled. Individual grains can be formed both randomly and manually, with significant similarity observed. The average number of vertices and sides and the size of the areas and angles were approximately the same. In random form, the particles are formed from convex polyhedrons. It is simple to detect concave regions on the face of particles that are points with stress concentration [24]. 


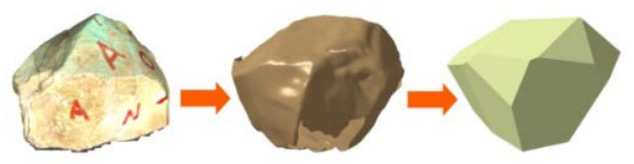

Figure 5. Digitizing a particle using 3D scanner [24]

A complete set of individual elements was created and loaded through a top plate. The plate moves down with constant velocity.

During the time period, the particles are able to move simply due to the high porosity of the sample. The lower the porosity, the less space the elements have for moving, and with this in parallel the percentage of breakage "action" is higher. During the unloading period, the forces (normal direction) decrease to null. Breakage can result peak values in forces that disappear in a few timesteps and they do not have relevant effect on the loading mechanism [24].
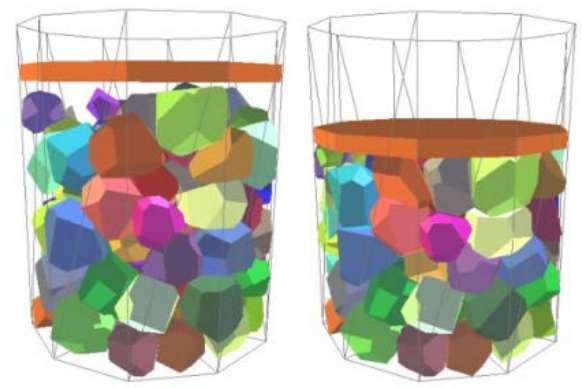

Figure 6. Loading a set of polyhedral individual particles in a vessel Left: Before load condition of the assembled model, Right: After load condition of the assembled model [25]

The model showed results close to reality and shown in Fig. 6 [25].

An assembly of ballast grains of unconventional shapes was taken into account and the angularity of the particles was simulated by grains: $2 \ldots 9$ regular (circle) grains were applied to formulate single grains of 12 various volumes. The grains are generated into random places. The assembly was calculated by $\mathrm{PFC}^{2 \mathrm{D}}$ (3.1), and the forces in the contacts were considered by gravity and compaction [26].

Using grains in the software, an initial analysis was made applying four various grain shapes (Fig. 7). Taking into account various value of radius of the component circle disks, the dimension of the grains was also modified to create the assembly of a requested grain size distribution. The grain generation in the PFC software can be 
of random or fixed sizes. In this research, the grain sizes were $19 \ldots 53 \mathrm{~mm}$. A box with dimensions $300 \times 600 \mathrm{~mm}$ was used.

Railway ballast material needs be considered according to their particle size distribution (PSD), with random manner (Fig. 8) [26].

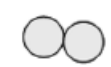

$$
\text { P-11 }
$$

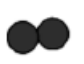

P-21

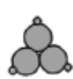

$\mathrm{P}-12$

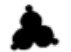

$\mathrm{P}-22$

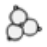

$$
\mathrm{P}-31
$$

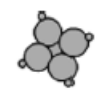

P-13

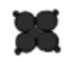

P-23

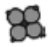

$\mathrm{P}-33$

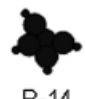

P-14

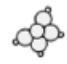

$\mathrm{P}-24$

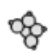

$\mathrm{P}-34$

Figure 7. Particle sizes and shapes considered in the numerical modelling [26]

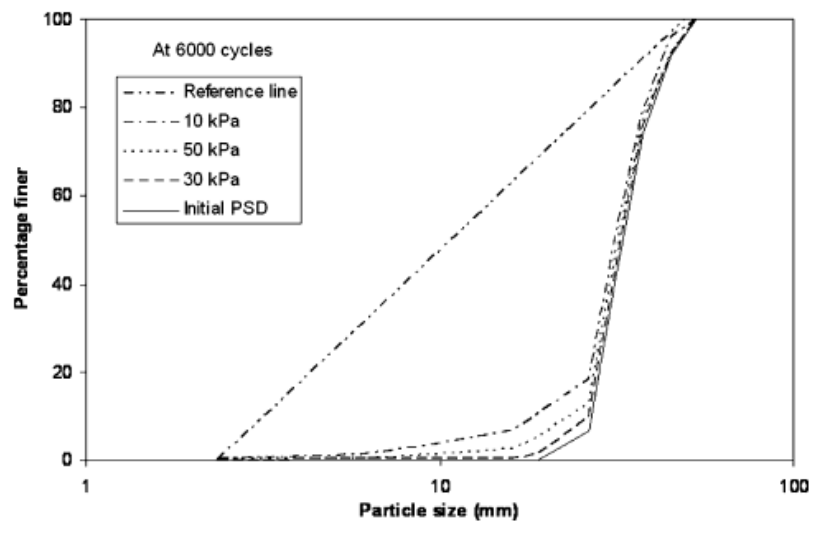

Figure 8. PSD at different confining pressure [26]

A cyclic loading analysis was executed for non-spherical grains. Relative low confining stress values were applied $(10,30$, as well as $50 \mathrm{kPa})$ in accordance with real circumstances. The PSD at different confining pressure is shown in Fig 8. The generated assembly of non-spherical grains under and after breakage can be seen in Fig. 9. 


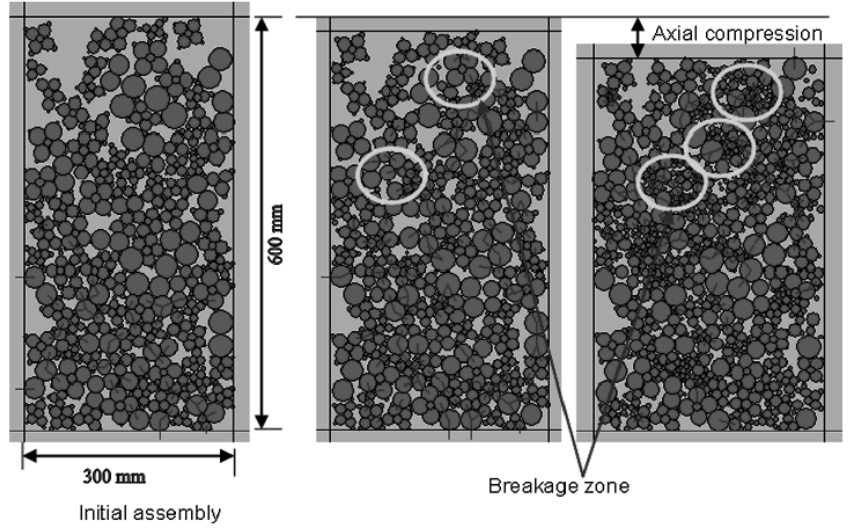

Figure 9. Some shots of assembly deformation including breakage [26]

In case the axial strain is higher than $4 \%$, dilatation of the grains can be discovered, because at low confining stress value (e.g., 5-10 kPa), high dilatation and breakage are referred primarily to the shearing and depreciation of angular projections regarding the significant high axial and radial strains [26]. The results are in accordance with experiments [26].

Higher degradation is obtained at a lower confining stress (i.e., $10 \mathrm{kPa}$ ). This trend is also similar to that of the results of esteemed authors. It was mentioned that at quite low confining stresses (and at places with the higher dilatation), grain degradation arisen primarily in this dilatation area, and it is only at much higher confining stress $\left(\sigma_{3}=50 \mathrm{kPa}\right)$ that degradation developed under compression [26].

\subsection{Numerical investigation of the material and tamping}

Ballast breakage and irrecoverable malformation (defect) occurred in ballasted tracks in case of high-speed and heavy loading railway vehicles. With EDEM 2.4. software, the authors documented a new numerical research of bulk material dynamics and the transient impaction of a system of non-regular polyhedral grains enclosed with a brick-shape box with a retaining wall applying them to simulate and model cyclic tamping. Ball packing methodology was used to simulate conventional real-size ballast grains. The methodology aimed to establish firm-soft coupling particle-flow tamping operation simulation numerical model based on contact dynamics theory.

Authors both introduced the contact dynamics (CD) methodology with both balls and also grains of balls. EDEM program can be applied for assembly of grains modelling and firm-soft coupling particle-flow tamping operation numerical model. 
They apply the ball grains stacking methodology to simulate the common grain model in EDEM program, which are shown in Fig. 10.

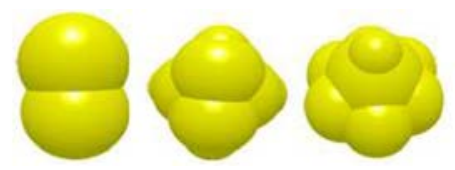

Figure 10. The particle models [27]

The main work when creating the system model included two parts and are shown in Fig. 11.:

- created a tamping bank 3D model

- choosing a track section unit with 3 ties as tamping simulation area and confine a particle factory with rectangular section in EDEM.

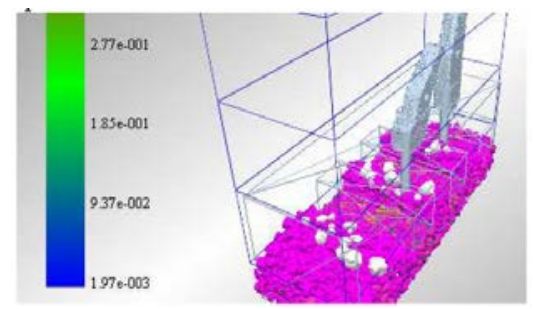

Figure 11. Simulation results of an assembled model in EDEM from tamping vibration [27]

Tamping hammers infiltrate into the ballast and press the grains under the ties in tamping cycle (the time consumption of one cycle is approximately 4 secs, the whole process contains 10 cycles). In reality, ties are buried on more than $15 \mathrm{~cm}$ depth general under the ballast track, but in the simulations a tie is on the top of the ballast [27].

The ball clump methodology is the basis grain modelling for DEM, i.e., ballast breakage during dynamic loadings. The simulation of this methodology illustrates the compression pressure during the cycle(s) and the local points of the railway track where the pressure is applied. Holding the purpose in sight, all of the transport modes and their specialities, and also to meet the increasing demand of public and freight transport, railway has a big challenge to develop the efficiency and lower its costs (maintenance, infrastructure). [28, 29]. 


\subsection{Summary of recent results}

Granular materials like railway ballast have plastic deformation caused by traffic load. DEM method can help reduce the rate of ballast bed obsolescence by creating simulations. This can also be used to reduce maintenance costs. DEM simulation has already been created for box tests with different layered ballast sets built up from clumps of particle shape. The displacements of the particles under the sleepers can be examined. [30]

Some studies suggest an analysis method for the interaction of the ballast and wheel based on DEM. Finite-element analysis (FEA) cannot be used for analysing track ballast because it consists of small separable particles. In contrast, other authors used the finite element method (FEM) to model and simulate the ballasted track for its reliability and convenience. Using the conventional FEM approach, the ballast is modelled as a shell or solid element, with the same material properties as the gravel layers in the two- or three-dimensional range. [31]

With the well-known Itasca PFC ${ }^{3 \mathrm{D}}$ software a series of DEM models were created. The set of the ballast was created from particles by clumping around 100 spheres together. The authors examined their macro- and microscopic performance by shearing with four different loads. Complex calibration procedures were performed to operate the simulations. [32]

Related to discrete element simulations, a lot of laboratory or field tests have to be conducted [33-37], these articles deal with the ballast, ballasted tracks as well as track-vehicle interaction. These kind of models can be simulated in sophisticated computer programs. To be able to achieve it, the micro- and macromechanical parameters have to be determined, after that calibration and validation of the model should be performed. A well-calibrated and validated model is suitable for calculation of special behaviour of ballast as well as ballasted tracks, e.g. stresses, strains, deformation, settlements, particle breakage, etc.

\section{Conclusions}

There is a very extensive literature on the subject, of which only a very tiny slice can be presented by the authors.

Numerous methods and methodologies are available thanks to the world's researchers. Based on the experience, both the researchers and the authors of this article are looking for correlations between the results experienced in real life and the simulations and constructed models developed using the computerized DEM method. It will be appreciated that laboratory and computer systems, although highly advanced, contain limitations and conditions. Users almost always must prepare a long list of which parameters they can take into account and which cannot. 
In many cases, measurements are difficult to reproduce due to individual laboratory and modelling conditions.

Since every research is different, the authors believe that it is always advisable to use a particular, ideal research method as there is no exact result or it is not clear which is the best solution first. They need to be personalized.

Ideally, characterizations are deterministic and human subjectivity is excluded. Furthermore, if the tools used are objective, they allow the production of repeatable results and work with as much information as possible.

Recent international literature [30-32] suggests that discrete element modelling will be indispensable for sophisticated modelling of granular sets in the future: both mechanically (micro as well as macro) and in terms of fragmentation.

Up-to-date articles [33-37] can be base of further, special numerical modelling problems.

\section{Acknowledgements}

The paper was written with the support of the project titled "Internationalisation, initiatives to establish a new source of researchers and graduates and development of knowledge and technological transfer as instruments of intelligent specialisations at Széchenyi István University" (project number: EFOP-3.6.1-16-2016-00017).

\section{References}

[1] B. Indraratna, N. T. Ngo, S. Nimbalkar, C. Rujikiatkamjorn, Two Decades of Advancement in Process Simulation Testing of Ballast Strength, Deformation and Degradation. In T. D. Stark, R. H. Swan \& R. Szecsy (Eds.), Railroad Ballast Testing and Properties, West Conshohocken, United States: ASTM International (2018) pp. 11-38. [cited 2021-01-30]

URL WWw.astm.org

[2] T. D. Stark, S. T. Wilk et al., Fouled Ballast Definitions and Parameters, American Railway Engineering and Maintenance of Way Association Annual Meeting 2017, Indianapolis, 2017 [cited 2021-01-30]

URL

https://wWw.researchgate.net/publication/319981870_Fouled Ballast_Definitions_and_Parameters

[3] M. A. Wnek, E. Tutumluer et al., Investigation of Aggregate Properties Influencing Railroad Ballast Performance, Transportation Research Record: 
Journal of the Transportation Research Board, Transportation Research Board of the National Academies, No. 2374 (2013) pp. 180-189. doi: https://doi.org/10.3141/2374-21

[4] G. P. Raymond, V. A. Diyaljee, Railroad ballast sizing and grading, Journal of the Geotechnical Engineering Division, 105(GT5) (1979) pp. 676-681. doi: https://doi .org/10.1061/(ASCE)GT.1943-5606.0001710

[5] E. T. Selig, J. M. Waters, Track Geotechnology and Substructure Management. Thomas Telford Publications, London, 1994.

[6] N. T. Ngo, B. Indraratna, C. Rujikiatkamjorn, Micromechanics-based investigation of fouled ballast using large-scale triaxial tests and discrete element modeling, Journal of Geotechnical and Geoenvironmental Engineering, 143 (2) (2017) pp. 04016089-1-04016089-16. doi: https ://doi.org/10.1061/(ASCE)GT.1943-5606.0001587

[7] R. J. Marsal R. J., Large scale testing of rockfill materials, Journal of Soil Mechanics and Foundation Engineering, 93(SM2) (1967) pp. 27-43.

[8] B. Indraratna, N. T. Ngo, C. Rujikiatkamjorn, Behavior of geogrid-reinforced ballast under various levels of fouling, Geotextiles and Geomembranes 29 (3) (2011) pp. 313-322.

doi: ht tps ://doi.org/10.1016/j . geotexmem. 2011.01.015

[9] I. Deiros, C. Voivret et al.. Quantifying Degradation of Railway Ballast using Numerical Simulations of Micro-Deval Test and In-situ conditions, Procedia Engineering (143) (2016) pp. 1016-1023.

doi: $h$ ttps://doi.org/10.1016/j.proeng.2016.06.096

[10] C. J. Coetzee, Review: Calibration of the discrete element method, Powder Technology, 310 (2017) pp. 104-142

doi: https ://doi.org/10.1016/j . powtec. 2017.01.015

[11] J.-P. Plassiard, N. Belheine, F.-V. Donze, A spherical discrete element model: calibration procedure and incremental response, Granular Matter 11 (5) (2009) pp. 293-306.

doi: https ://doi.org/10.1007/s10035-009-0130-x 
[12] J. Ai, J. F. Chen et al., Assessment of rolling resistance models in discrete element simulations, Powder Technology 206 (3) (2011) pp. 269-282. doi: https ://doi .org/10.1016/j . powtec. 2010.09.030

[13] D. Markauskas, A. Ramirez-Gomez et al., Maize grain shape approaches for DEM modelling, Computers and Electronics in Agriculture 118 (2015) pp. 247-258. doi: https ://doi .org/10.1016/j . compag . 2015. $09.0 \odot 4$.

[14] B. Saint-Cyr, E. Azema, J.-Y. Delenne, F. Radjai, P. Sornay, Effect of particle shape non-convexity on the rheology of granular media: 3D contact dynamics simulations, II. International Conference on Particle-based Methods - Fundamentals and Applications, Barcelona, 2011, pp. 1-8. [cited 2021-01-30]

URL https://www.researchgate.net/publication/267985633_Effect _of_Particle_Shape_non-Convexity_on_the_Rheology_of _ Granular_Media_3D_Contact_Dynamics_Simulations

[15] B. Zhou, R. Huang et al., DEM investigation of particle anti-rotation effects on the micromechanical response of granular materials, Granular Matter 15 (3) (2013) pp. 315-326. doi: $h$ ttps ://doi .org/10.1007/s10035-013-0409-9

[16] H. Li, G. R. McDowell, Discrete element modeling of under sleeper pads using a box test, Springer, Nottingham Centre for Geomechanics, Granular Matter 20 (2018) pp. 1-12. doi: https : //doi.org/10.1007/s10035-018-0795-๑

[17] K. Bagi, Á. Orosz, A new variable for characterising irregular element geometries in experiments and DEM simulations, Communications of the ECMS, Proceedings, 2020

ISBN 978-3-937436-68-5/978-3-937436-69-2(CD)

[18] J. M Rodriguez, T. Edeskär, S. Knutsson, Particle Shape Quantities and Measurement Techniques - A Review, EJGE (18) (2013) pp. 169-198. [cited 2021-01-30] URL https: //www. divaportal.org/smash/get/diva2:976352/FULLTEXT01.pdf 
[19] Z. Nie, Z. Liang, X. Wang, A three-dimensional particle roundness evaluation method, Springer, Granular Matter 20 (2018) pp. 1-11.

doi: https ://doi .org/10.1007/s10035-018-0802-5

[20] ITASCA Consultants GmbH, PFCTM Particle Flow Code software [cited 2021-01-30]

URL https://www.itasca.de/software/PFC

[21] DEM Solutions Ltd., EDEM Software software [cited 2021-01-30]

URL https://WWw. edemsimulation.com/software/

[22] YADE-DEM [cited 2021-01-30]

URL https://yade-dem.org/doc/

[23] E. Juhasz, R. M. Movahedi, I. Fekete, Sz. Fischer, Discrete Element Modelling of particle degradation of railway ballast material with $\mathrm{PFC}^{3 \mathrm{D}}$ software, Nauka Ta Progres Transportu 84 (6) (2019) pp. 103-116. doi: https://doi.org/10.15802/stp2019/194472

[24] Á. Orosz, J. P. Rádics, K. Tamás, Calibration of railway ballast DEM model, $31^{\text {st }}$ European Conference on Modelling and Simulation, Budapest, 2017, pp. $1-6$.

doi: $h t t p s$ ://doi.org/10.7148/2017- 0523

[25] Z. Hossain, B. Indraratna et al., DEM analysis of angular ballast breakage under cyclic loading, Geomechanics and Geoengineering: International Journal 2 (3) (2007) pp. 175-182.

doi: https ://doi .org/10.1080/17486020701474962

[26] X. Wang, B. Hua et al., The Research on the DEM Simulation of the Railway Ballast Tamping Process, Advanced Materials Research 724-725 (2013) pp. 1723-1726

doi: https://doi.org/10.4028/WWW. scientific.net/AMR. 724 725.1723

[27] X. Wang, B. Hua et al., Study on the Cyclic Loading Effects to the Railway Ballast, Advanced Materials Research 724-725 (2013) pp. 1736-1739 doi: https://doi.org/10.4028/WWW. scientific. net/AMR. 724 725.1736 
[28] G. R. McDowell, W. L. Lim, A. C. Collop, R. Armitage, N. H. Thom, Comparison of ballast index tests for railway trackbeds, Geotechnical Engineering 157(3) (2008) pp. 151-161.

doi: https://doi.org/10.1680/geng . 2004.157.3.151

[29] N. T. Ngo, B. Indraratna, C. Rujikiatkamjorn, DEM simulation of the behavior of geogrid stabilised ballast fouled with coal, Computers and Geotechnics 55 (2014) pp. 224-231.

doi: https ://doi .org/10.1016/j . compgeo. 2013.09.๑๑8

[30]H. Li, G. McDowell, Discrete element modelling of two-layered ballast in a box test, Granular Matter 22 (2020) pp. 1-14.

doi: $h t t p s$ ://doi .org/10.1007/s10035-020-01046-6

[31]L. Nam-Hyoung, K. Kyoung-Ju et al., DEM Analysis of Track Ballast Track Ballast-Wheel Interaction Simulation, Applied Sciences 10 (8) (2020) pp. 119.

doi: https ://doi.org/10.3390/app10082717

[32]Z. Hongyi, C. Jing, Numerical Study of Railway Ballast Subjected to Direct Shearing Using the Discrete Element Method, Advances in Materials Science and Engineering 20 (2020) pp. 1-13.

doi: $h$ ttps ://doi .org/10.1155/2020/3404208

[33] M. Sysyn, U. Gerber et al., A laboratory study of pressure distribution and residual settlements in wide grading double layer railway ballast under longterm cyclic loading, Archives of Civil Engineering 66 (4) (2020) pp. 561-578. doi: $h$ ttps://doi.org/10.24425/ace.2020.135237

[34] M. Przybylowicz,, M. Sysyn et al., Experimental and theoretical evaluation of side tamping method for ballasted railway track maintenance, Transport Problems 15 (3) (2020) pp. 93-106.

doi: https ://doi .org/10.21307/tp-2020-๑36

[35] M. Sysyn, O. Nabochenko, V. Kovalchuk, Experimental investigation of the dynamic behavior of railwaytrack with sleeper voids, Railway Engineering Science 28 (2) (2020) pp. 290-304.

doi: https ://doi.org/10.1007/s40534-๑20-00217-8 
[36]D. Kurhan, Y. Leibuk, Research of the Reduced Mass of the Railway Track, Acta Technica Jaurinensis 13 (4) (2020) pp. 324-341.

doi: https://doi.org/10.14513/actatechjaur.v13.n4.563

[37]D. Kurhan, Determination of Load for Quasi-static Calculations of Railway Track Stress-strain State, Acta Technica Jaurinensis 9 (1) (2016) pp. 83-96. doi: $h$ ttps://doi.org/10.14513/actatechjaur.v9.n1.400 